\title{
TEM CRAMS OF DISTINCTIVE NLO MATERIAL (SECOND HARMONIC GENERATIVE TYPE) BARIUM PARA NITROPHENOLATE(BPNP)
}

\author{
K SENTHIL KANNAN*, N BALASUBRAMANIAN ${ }^{1}$ \\ "FIRST AND CORRESPONDING AUTHOR: \\ Dr K SENTHIL KANNAN - (PROF. OF . PHYSICS) \\ ${ }^{1}$ DEPUTY VICE - CHANCELLER, St. EUGENE UNIVERSITY, LUSAKA, ZAMBIA

\section{ABSTRACT} \\ Single crystals of Barium para nitrophenolate sample has been grown by solution growth method and \\ Microscopic analysis - TEM is carried out for proper internal analysation and given here for reference. \\ The specimen has a special specification of SHG efficiency of more than 16 times than KDP [1] the single \\ $X R D$ data also given here for comparison and analysation of the materials.
}

\section{Key words}

Single crystals, Barium para nitrophenolate, Microscopy, XRD...

\section{INTRODUCTION}

Crystal growth necessitates solubility, preparation of homogeneous solutions, properties of solvents, saturation and super saturation of the solution grown specimen with the solute and solvent stoichiometry.

The experimental strategy to grow the crystals beneath assorted circumstances along with the kinetics and procedure of crystal chemistry is significant. Single crystals of the family of para nitro phenolates have drawn the notice of investigators over the past few time. Prose has reported that single crystals of barium para nitrophenolates have NLO efficiency sixteen times greater than that of KDP one.

\section{NLO}

Nonlinear optics (NLO) is the division that depicts the performance, medium in which the $\mathrm{P}$ as dielectric polarisation responds nonlinearly to the electric field $\mathrm{E}$ of the light. This nonlinearity is emblematically only examined at extremely elevated luminosity intensities (values of the electric field analogous to interatomic electric fields, typically of the value in $10^{8} \mathrm{~V} / \mathrm{m}$ ) such as those afforded by Laser source. 
In nonlinear optics, the superposition principle no longer grasps. An appraisal is there that status of the non-linear optical materials and devices, and their applications for optical signal processing and computing. Recent advances in engineering semiconductor microstructures are conversed and

shown to increase their non-linear optical susceptibilities in comparison with the immensity semiconductors.

Using the photorefractive matters as an instance, we define a set of figures of merit supported on the conditions from the optical devices for system functions. Using these figures of merit we estimate and confer the different photorefractive matters.

\section{SHG}

Second harmonic generation (SHG - also called frequency doubling) is a nonlinear optical progression, in which photons interacting with a nonlinear material are efficiently "shared" to form new photons with twice the energy, and therefore twice the frequency and half of the wavelength of the initial photons. It is a special case of frequency generation.

NLO applications involves the proper selection of the Crystal Parameters are Spectral Acceptance, Crystal Size, Walk-off Angle, Acceptance, Temperature Acceptance, Moisture, Phase-Matching Type and Angle Damage Threshold, Velocity Mismatching, Damage Threshold...

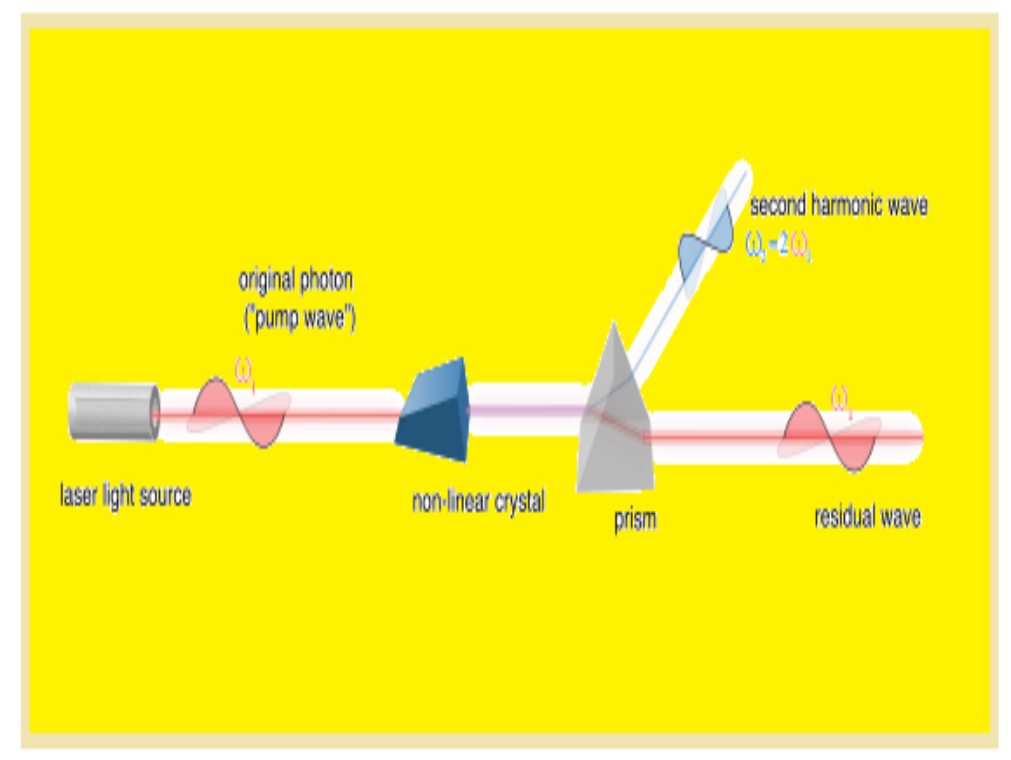

Fig.1.SHG Schematic output 


\section{EXPERIMENTAL}

\subsection{SINGLE CRYSTAL XRD DATA FOR BPNP}

Single crystal of barium para nitrophenolate is grown from aqueous solution by the slow evaporation technique. The crystal grown by this method is colored and has a growth period of four weeks. The single crystal is of dimension 10X10X7 $\mathrm{mm}^{3}$. The crystal materializes to be of excellent quality and is non hygroscopic in character [2].

\begin{tabular}{|l|l|}
\hline Empirical formula & $\mathrm{C}_{24} \mathrm{H}_{26} \mathrm{Ba} \mathrm{N}_{4} \mathrm{O}_{16}$ \\
\hline Formula weight & 763 \\
\hline $\begin{array}{l}\text { Crystal system, space } \\
\text { group }\end{array}$ & Orthorhombic, Fdd2 \\
\hline Unit cell dimensions & $\begin{array}{l}\text { a }=19.899 \AA \text { alpha }=90 \\
\text { deg. } \\
\text { b=28.019 } \AA \text { beta }=90 \\
\text { deg. } \\
\text { c= }=10.745 \AA \text { gamma }=90 \\
\text { deg. }\end{array}$ \\
& \\
\hline Volume & $5991 \AA^{3}$ \\
\hline
\end{tabular}




\subsection{TEM APPRAOCH FOR BPNP}

TEM - Transmission Electron Microscopy is a microscopy in which beam of electrons are transmitted through an ultra thin sample and interacting with the specimen it passes through it. TEM has superior resolution than other any other type of microscopes, owing to the small de Broglie wavelength of electrons. SEM is for surface morphology and TEM is for internal composition and its image projection is on a fluorescent screen.

The TEM approach of BPNP is given in the Fig.2. Since the spectral approach and SEM and AFM approaches of the crystal are already discussed in the previous journal paper [8], we hereby enclosed the TEM $100 \mathrm{~nm}$ approach of BPNP. Here, the crystal is approached for TEM and we observed that the crystal has no major flaws and free from defects and has clear inner infrastructural parameters of arrangements of atoms with micro apertures and few void space and spherical conglometry with quality NLO back ground and found to be efficient than KDP anisotropic.

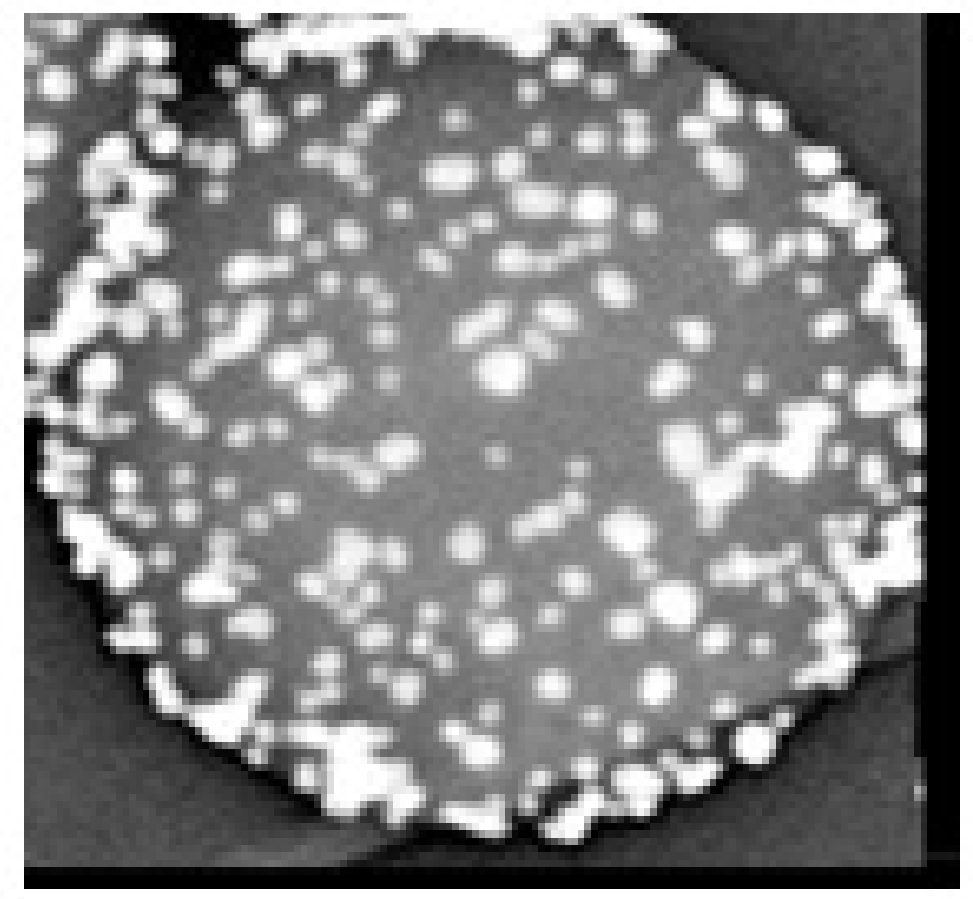

Fig.2. Tem Reprentation Of Bpnp 


\section{CONCLUSION}

Single crystals of barium para nitrophenolate $\left(\mathrm{C}_{4} \mathrm{H}_{26} \mathrm{BaN}_{4} \mathrm{O}_{16}\right)$ is grown by slow evaporation solution growth method. The grown crystals are subjected to various characterization studies and the results are presented and discussed. Single crystal X-ray

diffraction study reveals the crystal forms to be in orthorhombic system as $a \neq b \neq c$ and $\alpha=\beta=\gamma=90^{\circ}$.

TEM Microscopic analysis confirms the growth of barium para nitrophenolate single crystal with good quality and reveals that the crystal is free from flaws observed that the crystal has no major flaws and free from defects and has clear inner infrastructural parameters of arrangements of atoms with micro apertures and few void space and spherical conglometry with quality NLO back ground and found to be efficient than KDP anisotropic [5, 6, and 7].

\section{ACKNOWLEGEMNT}

The authors would like to thank the BS Abdur Rahman Crescent University for characterisations and St.Eugene Univ. authorities for the proper publication of this research work and for their permission rendered.

\section{REFERENCES}

1. Bordui (1987),"'Growth of large single crystals from aqueous solutions," J.Crys.Growth, Vol. 85, pp 199-205.

2. Deepa.M, Rajendra Babu et al (1994), "Growth and characterization of calcium pyprophosphate dehydrate grown in silica gel," Bull. of, Mater Science, Vol. 17, pp. 105-108.

3. Kasthuri Bangera .V et al (1992), "Growth and characterization of Barium Copper Oxalate single crystals in Gels", Bull. Mater. Science, Vol .15, pp 339-341.

4. Manimekalai.R, Balakrishnan et al (1994), "Growth and characterization of pure and doped lead hydrogen phosphate single crystals in Silica gel," Cryst. Res . Tech., Vol. 29, pp $795-800$.

5. Robert M.C., Lefaucheux .F (1988), "Crystals growth in gels: principle and application Journal of crystal growth," Vol. 90, pp. $358-367$

6. Test book of Atomic and Molecular spectroscopy, Mool chand Gupta S.Chand Publications.

7. Haja Hameed.A.S.,Ravi.G(2005), "Studies on Amino Acids admixture triglycine sulphosphate crystals," J.Crys. Growth, Vol. 275, pp. 1461- 1465. 
8. K.SenthilKannan et al (2013), "Spectral and micro crams of unique nlo material (barium para nitrophenolate)"Vol I issue 2 161-166.

\section{BIBILIOGRAPHY}

Prof. Dr N Balasubramanian M.A(Eng.)., M.Ed., M.Sc (Psy)., M.Phil., Ph.D., PGDCA., B.Ed., is having four decades of experience in University teaching and having publications 25+ International and 50+ National in Peer reviewed Journals and more than 100+ publications in International and National conferences / seminars and invited talks... and guided candidates for Ph.D as 18 and M.Phil as 38 and M.Ed as 35 .

Dr K SENTHIL KANNAN M.Sc., SLET., M.Phil., Ph.D., in PHYSICS and completed M.B.A., M.A., C.I., PGDCA., B.Ed., D.C.H., D.C.A., is having two decades of experience in University / College teaching and having publications 34+ International and 1 National in Peer reviewed Journals and more than 90+ publications in International and National conferences / seminars and invited talks... and published 5 books and reviewer for 5+ International Journals and guided candidates for M.Phil as 6 and M.Sc as 55 and student's projects for Inter and Intra state as 100+ 